\title{
MODEL GENERALIZED SPACE TIME AUTOREGRESSIVE $(1,1)$ PADA DATA CURAH HUJAN
}

\author{
Ihzal Muhaini, Dadan Kusnandar, Nurfitri Imro’ah
}

\begin{abstract}
INTISARI
Generalized Space Time Autoregressive (GSTAR) adalah salah satu model yang digunakan untuk menganalisis data yang mempunyai ketergantungan lokasi dan waktu. Model GSTAR menghasilkan model ruang waktu yang mengadopsi tahapan-tahapan model Autoregressive Integrated Moving Average (ARIMA). Studi kasus yang digunakan pada penelitian ini adalah data curah hujan di Kota Pontianak, Kabupaten Mempawah dan Kabupaten Kubu Raya dengan periode waktu dari bulan Januari 2008 hingga bulan Desember 2012. Penelitian ini menggunakan prinsip parsimony model, sehingga model yang digunakan adalah GSTAR(1,1). Pendugaan parameter pada model GSTAR(1,1) dilakukan menggunakan metode Ordinary Least Square $(O L S)$ dengan bobot normalisasi korelasi silang. Hasil perhitungan nilai MAPE AR(1) dan GSTAR(1,1) terlalu besar, sehingga model tidak cocok digunakan untuk peramalan pada tiga lokasi.
\end{abstract}

Kata kunci: deret waktu, GSTAR, bobot normalisasi korelasi silang

\section{PENDAHULUAN}

Kalimantan Barat merupakan salah satu provinsi di Indonesia yang berada diantara garis $2^{0} 08^{\prime} \mathrm{LU}$ dan $3^{0} 05^{\prime}$ LS serta diantara $108^{\circ} 0^{\prime}$ BT dan $114^{\circ} 10^{\prime}$ BT [1]. Karena pengaruh letak ini pula, maka Kalimantan Barat adalah salah satu daerah tropik dengan suhu udara cukup tinggi serta diiringi kelembaban yang tinggi. Berdasarkan letak geografis yang spesifik ini maka daerah Kalimantan Barat tepat dilalui oleh garis Khatulistiwa (garis lintang $0^{0}$ ) tepatnya di atas Kota Pontianak, sehingga perubahan cuaca menjadi tidak menentu. Oleh karena itu peneliti menganalisis pola curah hujan di beberapa kota/kabupaten Kalimantan Barat dengan menggunakan metode statistik.

Salah satu metode yang digunakan untuk menganalisis pola curah hujan ini adalah model Generalized Space Time Autoregressive (GSTAR). GSTAR adalah salah satu bentuk khusus dari model Autoregressive (AR) dan model Vector Autoregressive (VAR). Model autoregressive (AR) adalah suatu bentuk regresi tetapi bukan yang menghubungkan variabel tak bebas, melainkan menghubungkan nilai-nilai sebelumnya pada time lag [2]. Jadi, suatu model autoregressive menyatakan suatu ramalan sebagai fungsi nilai-nilai sebelumnya dari deret waktu tertentu. Kemudian model VAR adalah suatu sistem persamaan yang memperlihatkan setiap variabel sebagai fungsi linier dari konstanta dan nilai lag dari variabel yang ada dalam sistem. Model STAR merupakan suatu model yang dikategorikan berdasarkan lag yang berpengaruh secara linier, baik dalam lokasi maupun waktu. Model STAR hanya dapat digunakan untuk lokasi yang homogen, dengan mengasumsikan parameter autoregressive dan estimasi parameter adalah sama untuk setiap lokasi (spasial) [3].

Penelitian ini mengambil data sekunder di Badan Meteorologi Klimatologi dan Geofisika (BMKG) secara online di Stasiun Meteorologi Maritim Pontianak, Stasiun BMKG Meteorologi Kelas II Siantan Pontianak dan Stasiun Meteorologi Kelas I Supadio Pontianak. Tahapan awal dalam melakukan penelitian adalah melakukan identifikasi awal data deret waktu untuk memperkecil kekeliruan model, jika data belum stasioner dalam rata-rata maka data tersebut differencing satu kali, lakukan differencing yang kedua jika data belum stasioner hingga data menjadi stasioner. Berikutnya melakukan estimasi parameter dengan metode kuadrat terkecil menggunakan Software R. Kemudian uji diagnosis untuk melihat apakah galat (error) yang dihasilkan sudah berdistribusi normal dan uji stasioner estimasi parameter. 


\section{MODEL AUTOREGRESSIVE}

Autoregressive (AR) adalah suatu bentuk regresi tetapi bukan yang menghubungkan variabel tak bebas, melainkan menghubungkan nilai-nilai $Z_{t-p}$ pada time lag. Model Autoregressive (AR) dengan orde $p$ dinotasikan $\operatorname{AR}(p)$. Bentuk umum model $\operatorname{AR}(p)$ sebagai berikut:

$$
Z_{t}=\phi_{1} Z_{t-1}+\phi_{2} Z_{t-2}+\phi_{3} Z_{t-3}+\ldots+\phi_{p} Z_{t-p}+e_{t}
$$

dimana $Z_{t}$ adalah variabel pengamatan pada waktu ke- $t, \phi_{p}$ adalah parameter autoregressive ke- $p$, dan $e_{t}$ adalah nilai kesalahan pada waktu ke- $t$ [4].

\section{MODEL VECTOR AUTOREGRESSIVE (VAR)}

Model Vector Autoregressive (VAR) adalah model time series multivariat. Misal VAR orde-1, VAR(1) adalah sebagai berikut:

$\left(\mathbf{I}-\boldsymbol{\Phi}_{1} \mathbf{B}\right) \mathbf{Z}_{t}=\mathbf{e}_{t}$, dimana $\mathbf{B}$ adalah backward shift operator

atau

$$
\mathbf{Z}_{t}=\mathbf{\Phi}_{1} \mathbf{Z}_{t-1}+\mathbf{e}_{t}
$$

dimana $e \sim N(0, \Sigma)$, dimana $\sum$ matriks varian kovarian $m \times m$ simetri, definit positif. Proses white noise diasumsikan $\sum=\sigma^{2} I_{m}$.

\section{MODEL GENERALIZED SPACE TIME AUTOREGRESSIVE (GSTAR)}

Model GSTAR menghasilkan model ruang waktu (space time) dimana model ruang waktu ini mengadopsi tahapan-tahapan model Autoregressive Intergrated Average (ARIMA) atau biasa disebut Box-Jenkins yang dikembangkan oleh George Box dan Gwilym Jenkins tahun 1976. Model GSTAR biasa digunakan pada lokasi dengan sifat heterogen dengan parameter-parameter yang tidak harus sama untuk faktor waktu maupun lokasi.

Dalam notasi matriks model yang umum GSTAR, misalnya orde ke- $p$ dalam time dan orde $\ell=0,1, \ldots, \lambda_{k}$ dalam space dituliskan sebagai:

$$
\mathbf{Z}(t)=\sum_{k=1}^{p} \sum_{\ell=0}^{\lambda_{k}} \boldsymbol{\Phi}_{k \ell} \mathbf{W}^{(\ell)} \mathbf{Z}(t-k)+\mathbf{e}(t)
$$

dimana $k$ adalah orde waktu autoregressive $(k=1,2, \ldots, \mathrm{p}), \ell$ adalah orde spasial autoregressive $(\ell=$ $\left.0,1,2, \ldots, \lambda_{k}\right)$ dan $e(t)$ adalah vektor error yang berukuran $N \times 1$ yang diasumsikan berdistribusi normal, $\boldsymbol{\Phi}_{k \ell}$ adalah matriks parameter GSTAR berukuran $N \times N$ pada lag waktu (time) $k$ dan lag spasial $\ell, \mathbf{W}^{(\ell)}$ adalah matriks bobot ukuran $N \times N$ pada lag spasial $\ell$ (dimana $\ell=0,1$ ).

\section{PEMBOBOTAN LOKASI MODEL GSTAR $(1,1)$}

Pemilihan bobot lokasi adalah salah satu permasalahan utama dalam pemodelan GSTAR. Metode yang digunakan sebagai pembobot lokasi dalam GSTAR salah satunya adalah bobot normalisasi korelasi silang. Berikut ini bentuk taksiran korelasi silang pada data sampel:

$$
r_{i j}(k)=\frac{\sum_{t=k+1}^{n}\left[Z_{i}(t)-\bar{Z}_{i}\right]\left[Z_{j}(t)-\bar{Z}_{j}\right]}{\sqrt{\left(\sum_{t=1}^{n}\left[Z_{i}(t)-\bar{Z}_{i}\right]^{2}\right)\left(\sum_{t=1}^{n}\left[Z_{j}(t)-\bar{Z}_{j}\right]^{2}\right)}}
$$

dimana, koefisien $r_{i j}(k)$ merupakan korelasi silang kejadian di lokasi ke-i dan ke-j [4]. Selanjutnya penentuan bobot lokasi dengan normalisasi silang antar lokasi pada waktu yang bersesuaian. Berikut ini rumus bobot normalisasi korelasi silang:

$$
W_{i j}{ }^{(k)}=\frac{r_{i j}(k)}{\sum_{K \neq i}\left|r_{i K}{ }^{(k)}\right|}
$$


dimana $i \neq j$, dan $\sum_{j \neq i}\left|w_{i j}\right|=1$.

Bobot ini memberikan fleksibilitas pada besar dan tanda hubungan antar lokasi yang bisa berlainan yang positif dan negatif [6].

\section{ESTIMASI PARAMETER LEAST SQUARE PADA MODEL GSTAR(1,1)}

Model GSTAR dapat dinyatakan sebagai suatu model linier dan peramalan dari parameterparameter autoregressive. Estimasi parameter model GSTAR dapat dilakukan dengan menggunakan metode OLS yaitu dengan meminimalkan jumlah kuadrat sisaan. Berikut persamaan model $\operatorname{GSTAR}(1,1)$ :

$$
\mathbf{Z}(t)=\sum_{k=1}^{p} \sum_{\ell=0}^{\lambda_{k}} \boldsymbol{\Phi}_{k \ell} \mathbf{W}^{(\ell)} \mathbf{Z}(t-k)+\mathbf{e}(t)
$$

Atau dapat ditulis dalam bentuk matriks sebagai berikut:

$$
\left[\begin{array}{l}
Z_{1}(t) \\
Z_{2}(t) \\
Z_{3}(t)
\end{array}\right]=\left[\begin{array}{ccc}
\phi_{10} & 0 & 0 \\
0 & \phi_{20} & 0 \\
0 & 0 & \phi_{30}
\end{array}\right]\left[\begin{array}{l}
Z_{1}(t-1) \\
Z_{2}(t-1) \\
Z_{3}(t-1)
\end{array}\right]+\left[\begin{array}{ccc}
\phi_{11} & 0 & 0 \\
0 & \phi_{21} & 0 \\
0 & 0 & \phi_{31}
\end{array}\right]\left[\begin{array}{ccc}
0 & w_{12}{ }^{(1)} & w_{13}{ }^{(1)} \\
w_{21}{ }^{(1)} & 0 & w_{23}{ }^{(1)} \\
w_{31}{ }^{(1)} & w_{32}{ }^{(1)} & 0
\end{array}\right]\left[\begin{array}{l}
Z_{1}(t-1) \\
Z_{2}(t-1) \\
Z_{3}(t-1)
\end{array}\right]+\left[\begin{array}{l}
e_{1}(t) \\
e_{2}(t) \\
e_{3}(t)
\end{array}\right]
$$

Sehingga terbentuk persamaan:

$$
\begin{aligned}
& Z_{1}(t)=\phi_{10} Z_{1}(t-1)+\phi_{11} w_{12} Z_{2}(t-1)+\phi_{11} w_{13} Z_{3}(t-1)+e_{1}(t) \\
& Z_{2}(t)=\phi_{20} Z_{2}(t-1)+\phi_{21} w_{21} Z_{1}(t-1)+\phi_{21} w_{23} Z_{3}(t-1)+e_{2}(t) \\
& Z_{3}(t)=\phi_{30} Z_{3}(t-1)+\phi_{31} w_{31} Z_{1}(t-1)+\phi_{31} w_{32} Z_{2}(t-1)+e_{3}(t)
\end{aligned}
$$

dengan $V_{N}(t)=\sum_{j=1}^{i} W_{i j} Z_{j}(t)$. Model untuk lokasi ke- $i$ dapat dinyatakan dengan $Z=Z^{*} \phi+e$. Sehingga estimasi parameter model $\operatorname{GSTAR}(1,1)$ adalah sebagai berikut:

$$
\left[\begin{array}{l}
Z_{1}(t) \\
Z_{2}(t) \\
Z_{3}(t)
\end{array}\right]=\left[\begin{array}{cccccc}
Z_{1}(t-1) & 0 & 0 & V_{1}(t-1) & 0 & 0 \\
0 & Z_{2}(t-1) & 0 & 0 & V_{2}(t-1) & 0 \\
0 & 0 & Z_{3}(t-1) & 0 & 0 & V_{3}(t-1)
\end{array}\right]\left[\begin{array}{c}
\phi_{10} \\
\phi_{20} \\
\phi_{30} \\
\phi_{11} \\
\phi_{21} \\
\phi_{31}
\end{array}\right]+\left[\begin{array}{l}
e_{1}(t) \\
e_{2}(t) \\
e_{3}(t)
\end{array}\right]
$$

dengan:

$$
\begin{aligned}
Z & =\left[\begin{array}{l}
Z_{1}(t) \\
Z_{2}(t) \\
Z_{3}(t)
\end{array}\right], Z^{*}=\left[\begin{array}{cccccc}
Z_{1}(t-1) & 0 & 0 & V_{1}(t-1) & 0 & 0 \\
0 & Z_{2}(t-1) & 0 & 0 & V_{2}(t-1) & 0 \\
0 & 0 & Z_{3}(t-1) & 0 & 0 & V_{3}(t-1)
\end{array}\right] \\
\phi & =\left[\begin{array}{l}
\phi_{10} \\
\phi_{20} \\
\phi_{30} \\
\phi_{11} \\
\phi_{21} \\
\phi_{31}
\end{array}\right], \text { dan } e=\left[\begin{array}{l}
e_{1}(t) \\
e_{2}(t) \\
e_{3}(t)
\end{array}\right]
\end{aligned}
$$

sehingga koefisien regresi $\phi$ dapat ditaksir menggunakan OLS dengan rumus sebagai berikut: 


\section{ANALISIS CURAH HUJAN}

$$
\hat{\phi}=\left(Z^{* T} Z^{*}\right)^{-1}\left(Z^{* T} Z\right)
$$

Data yang digunakan dalam penelitian ini adalah data curah hujan bulanan dalam satuan milimeter ( $\mathrm{mm}$ ) di Kota Pontianak, Kabupaten Mempawah dan Kabupaten Kubu Raya. Jenis data yang digunakan adalah data sekunder yang didapatkan secara online dari data BMKG Nasional, data diambil dari bulan Januari 2008 hingga Desember 2012. Salah satu cara yang dapat dilakukan untuk mendeskripsikan suatu data adalah dengan penyajian data melalui tabel. Berikut ini deskriptif data curah hujan dimulai dari mean, standar deviasi, nilai minimum dan nilai maksimum:

Tabel 1 Deskriptif data curah hujan bulanan (mm)

\begin{tabular}{lcccc}
\hline \multicolumn{1}{c}{ Lokasi } & Mean & StDev & Min & Max \\
\hline Kota Pontianak & 9,01 & 4,24 & 2,97 & 19,77 \\
Kabupaten Mempawah & 8,33 & 4,51 & 1,25 & 19,88 \\
Kabupaten Kubu Raya & 9,52 & 4,83 & 1,93 & 23,86 \\
\hline
\end{tabular}

Berdasarkan Tabel 1 dapat diketahui bahwa rata-rata curah hujan terendah adalah di Kabupaten Mempawah, dengan rata-rata curah hujan sebesar $8,33 \mathrm{~mm} / \mathrm{bulan}$ dan rata-rata curah hujan tertinggi di Kabupaten Kubu Raya sebesar 9,52 mm/bulan. Artinya, rata-rata curah hujan per bulan di Kabupaten Mempawah lebih rendah dibandingkan dengan 2 wilayah lainnya.

\section{IDENTIFIKASI STASIONERITAS}

Identifikasi stasioneritas diperlukan untuk melihat kestasioneran data supaya dapat dilanjutkan pada analisis berikutnya. Untuk mengidentifikasi kestasioneran data penelitian ini menggunakan diagram plot. Berikut ini plot curah hujan tiga lokasi:

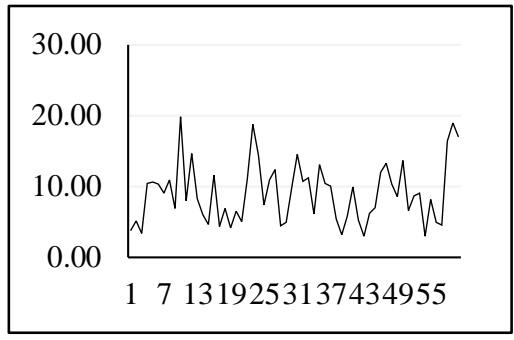

(a) Kota Pontianak

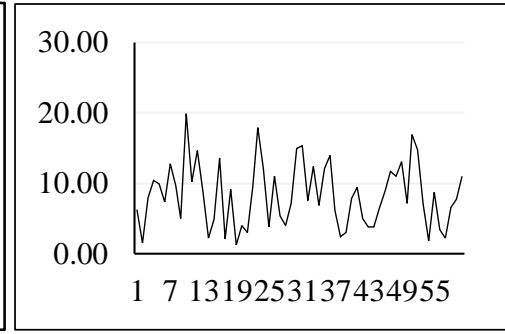

(b) Kabupaten Mempawah

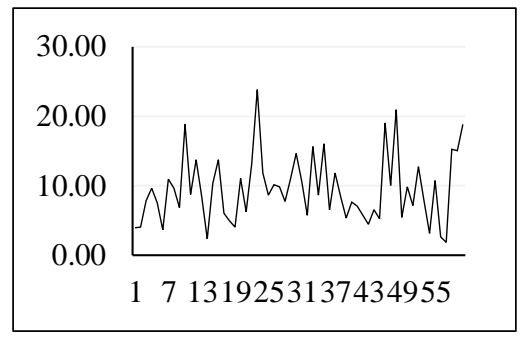

(c) Kabupaten Kubu Raya

Gambar 1 Plot data curah hujan bulanan (mm)

Gambar 1 menunjukkan data terlihat berada di garis rata-rata artinya data sudah stasioner dalam mean.

\section{AUTOREGRESSIVE ORDE 1}

Autoregressive digunakan untuk menghitung nilai estimasi dengan menggunakan dari time lag sebelumnya. Hasil perhitungan parameter AR(1) menggunakan SPSS sebagai berikut:

Tabel 2 Estimasi parameter AR(1)

\begin{tabular}{lccc}
\hline \multicolumn{1}{c}{ Lokasi } & Nilai estimasi & Sig. & Signifikansi \\
\hline Kota Pontianak & 0,31 & 0,02 & Signifikan \\
Kabupaten Mempawah & 0,21 & 0,10 & Tidak signifikan \\
Kabupaten Kubu Raya & 0,08 & 0,55 & Tidak signifikan \\
\hline
\end{tabular}

Berdasarkan Persamaan (1) sehingga didapatkan model AR(1) sebagai berikut:

Kota Pontianak $\quad: Z_{t}=0,31\left(Z_{t-1}\right)$ 
Kabupaten Mempawah : $Z_{t}=0,21\left(Z_{t-1}\right)$

Kabupaten Kubu Raya : $Z_{t}=0,08\left(Z_{t-1}\right)$

\section{PERBANDINGAN DATA AKTUAL DAN ESTIMASI AR(1)}

Perbandingan data aktual dan estimasi berfungsi untuk melihat perbedaan data aktual dengan estimasi. Berikut hasil perbandingan data aktual dan estimasi model AR(1):

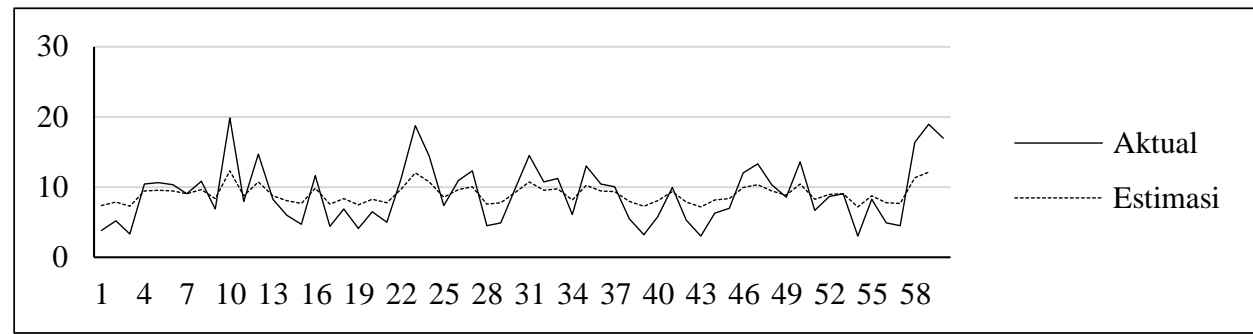

(a) Kota Pontianak

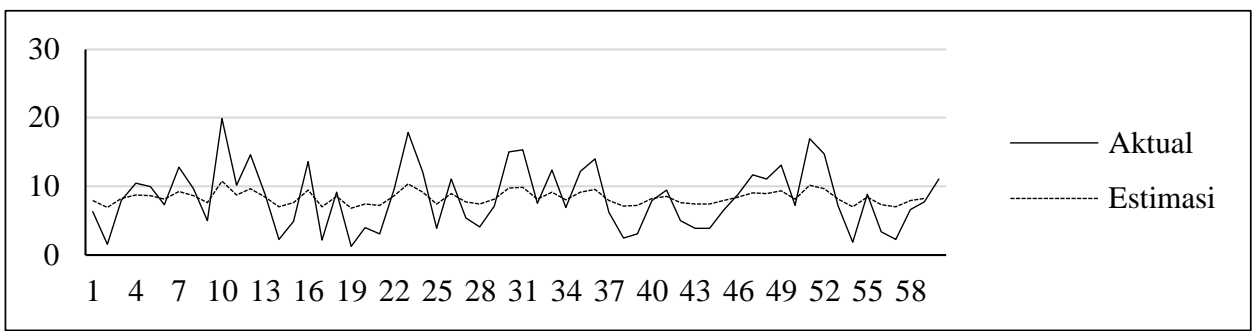

(b) Kabupaten Mempawah

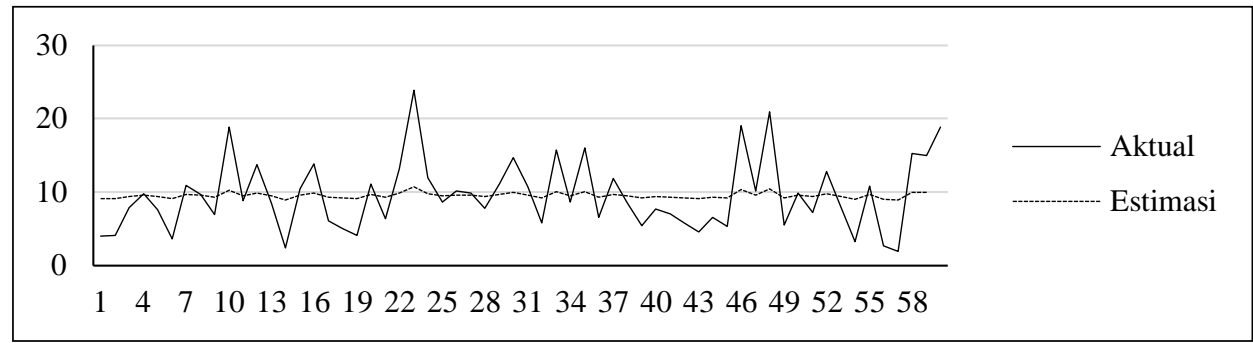

(c) Kabupaten Kubu Raya

Gambar 2 Perbandingan data aktual dan estimasi model Autoregressive pada orde satu

Berdasarkan Gambar 2 di tiga lokasi terlihat data estimasi cukup jauh berbeda dengan data aktual. Sehingga model AR(1) tidak cocok digunakan pada tiga lokasi.

\section{BOBOT NORMALISASI KORELASI SILANG}

Untuk menghitung bobot normalisasi korelasi silang langkah pertama yang dilakukan adalah dengan cara menghitung nilai korelasi antar lokasi, berikut hasil perhitungan korelasi lokasi berdasarkan Persamaan (3):

$$
R=\left[\begin{array}{ccc}
1 & 0,66 & 0,72 \\
0,66 & 1 & 0,61 \\
0,72 & 0,61 & 1
\end{array}\right]
$$

Setelah mendapatkan nilai korelasi, selanjutnya mencari nilai bobot normalisasi korelasi silang. Bobot normalisasi korelasi silang dihitung berdasarkan rumus Persamaan (4). Hasil bobot normalisasi korelasi silang sebagai berikut: 


$$
W=\left[\begin{array}{ccc}
0 & 0,48 & 0,52 \\
0,52 & 0 & 0,48 \\
0,54 & 0,46 & 0
\end{array}\right]
$$

\section{ESTIMASI NILAI PARAMETER DAN MODEL GSTAR(1,1)}

Model GSTAR $(1,1)$ dapat dinyatakan sebagai suatu model linier dan peramalan dari parameterparameter autoregressive. Estimasi parameter model GSTAR dapat dilakukan dengan menggunakan metode OLS yaitu dengan meminimalkan jumlah kuadrat sisaan. Berikut hasil estimasi parameter dan tingkat signifikansi model GSTAR $(1,1)$ menggunakan aplikasi $R$ :

Tabel 3 Nilai parameter dan signifikansi

\begin{tabular}{ccc}
\hline Parameter & Nilai estimasi & Standar error \\
\hline$\phi_{10}$ & 0,22 & 8,61 \\
$\phi_{20}$ & 0,06 & 5,56 \\
$\phi_{30}$ & 0,03 & 5,73 \\
$\phi_{11}$ & 0,11 & 7,56 \\
$\phi_{21}$ & 0,26 & 7,66 \\
$\phi_{31}$ & 0,09 & 8,09 \\
\hline
\end{tabular}

Hasil dari Tabel 3 diketahui nilai standar error masing-masing parameter cukup besar, hal ini menunjukkan bahwa estimasi parameter tidak cukup baik digunakan pada model $\operatorname{GSTAR}(1,1)$. Sehingga model GSTAR $(1,1)$ berdasarkan Persamaan (5) sebagai berikut:

$$
\begin{aligned}
Z_{1}(t) & =0,22 Z_{1}(t-1)+(0,11 \times 0,48) Z_{2}(t-1)+(0,11 \times 0,52) Z_{3}(t-1) \\
& =0,22 Z_{1}(t-1)+0,05 Z_{2}(t-1)+0,06 Z_{3}(t-1) \\
Z_{2}(t) & =0,06 Z_{2}(t-1)+(0,26 \times 0,52) Z_{1}(t-1)+(0,26 \times 0,48) Z_{3}(t-1) \\
& =0,06 Z_{2}(t-1)+0,14 Z_{1}(t-1)+0,12 Z_{3}(t-1) \\
Z_{3}(t) & =0,03 Z_{3}(t-1)+(0,09 \times 0,54) Z_{1}(t-1)+(0,09 \times 0,46) Z_{2}(t-1) \\
& =0,03 Z_{3}(t-1)+0,05 Z_{1}(t-1)+0,04 Z_{2}(t-1)
\end{aligned}
$$

Kemudian perhitungan estimasi GSTAR(1,1) menggunakan Microsoft Office Excel. Berikut ini hasil perhitungan estimasi model dan dibandingkan dengan data aktual:

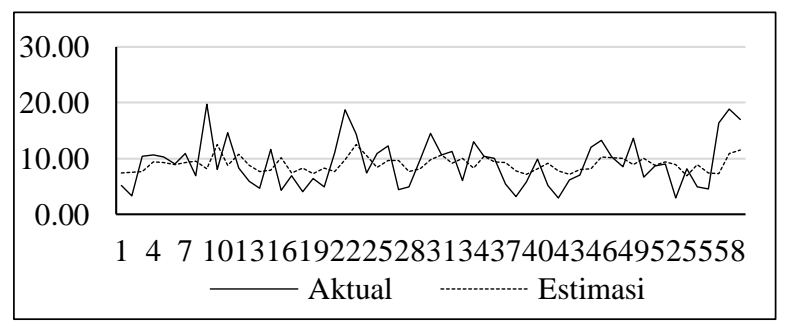

a) Kota Pontianak

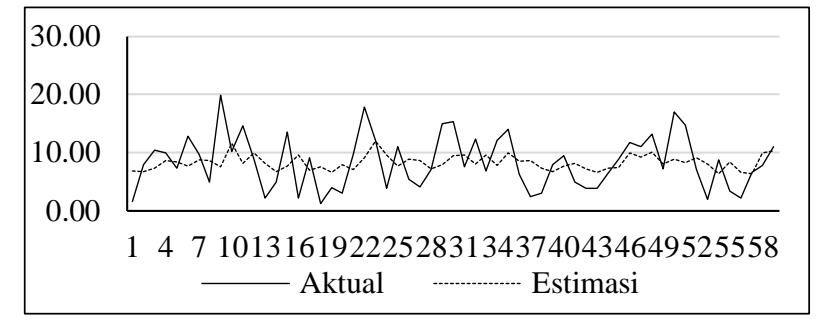

b) Kabupaten Mempawah 


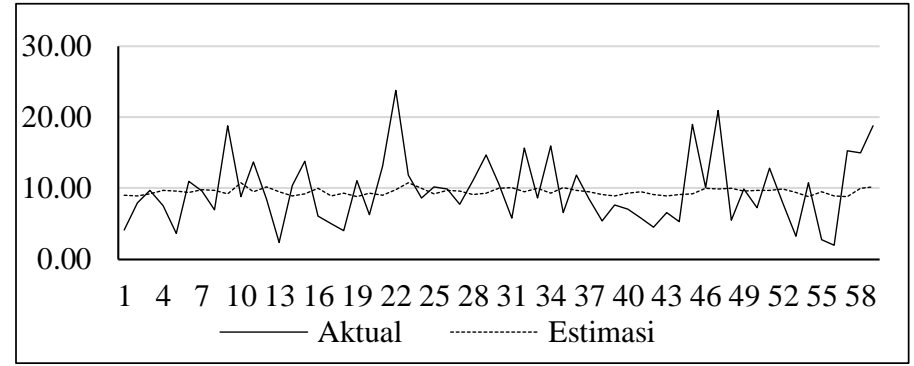

c) Kabupaten Kubu Raya

Gambar 3 Data estimasi curah hujan bulanan (mm)

Berdasarkan Gambar 3 dapat diketahui bahwa hasil estimasi tiga lokasi cukup jauh berbeda dengan data aktual. Hal ini menunjukkan bahwa model GSTAR $(1,1)$ tidak cocok digunakan pada tiga lokasi.

\section{UJI DIAGNOSTIK}

Uji diagnostik dilakukan menggunakan uji $Q Q$-Plot nilai residual dan uji stasioner parameter. Kemudian uji normalitas data error GSTAR $(1,1)$ menggunakan uji QQ-Plot dengan aplikasi SPSS, hasilnya sebagai berikut:

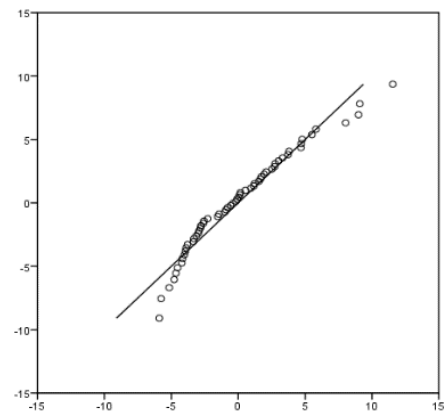

a) Kota Pontianak

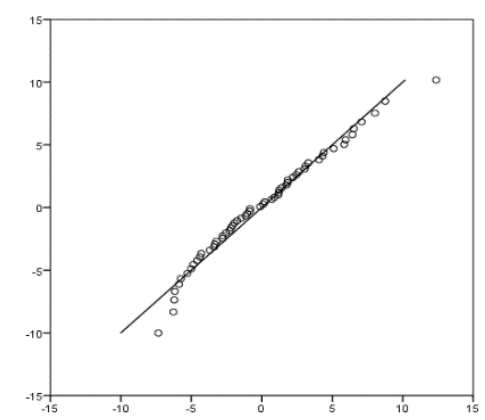

b) Kabupaten Mempawah

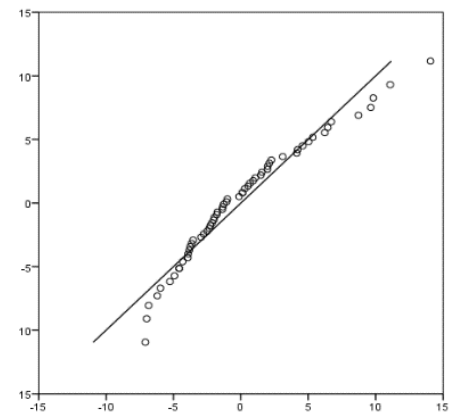

c) Kabupaten Kubu Raya

\section{Gambar 4 Grafik $Q Q-P l o t$}

Berdasarkan Gambar 4 dapat diketahui bahwa data residual tidak normal karena titik-titik data berada di luar garis diagonal. Kemudian uji stasioner parameter berdasarkan Tabel 3 didapatkan bahwa data sudah stasioner karena $\left|\phi_{10} \pm \phi_{11}\right| \leq 1,\left|\phi_{20} \pm \phi_{21}\right| \leq 1$ dan $\left|\phi_{30} \pm \phi_{31}\right| \leq 1$ [7].

\section{PERBANDINGAN MAPE AR(1) DAN GSTAR(1,1)}

Menghitung perbandingan nilai MAPE dari AR(1) dan $\operatorname{GSTAR}(1,1)$ didapatkan sebagai berikut:

Tabel 4 Nilai MAPE AR(1) dan GSTAR(1,1)

MAPE

Lokasi

$\operatorname{AR}(1) \quad \operatorname{GSTAR}(1,1)$

\begin{tabular}{lll}
\hline Kota Pontianak & $45 \%$ & $\mathbf{4 4 \%}$ \\
Kabupaten Mempawah & $78 \%$ & $\mathbf{7 5 \%}$ \\
Kabupaten Kubu Raya & $56 \%$ & $\mathbf{5 5 \%}$ \\
\hline
\end{tabular}


Berdasarkan Tabel 4 hasil perbandingan nilai MAPE model AR(1) dan GSTAR(1,1) dapat diketahui bahwa model GSTAR $(1,1)$ pada tiga lokasi penelitian memiliki nilai MAPE yang sedikit lebih kecil dari AR(1). Namun, nilai MAPE model GSTAR(1,1) juga tidak cukup baik digunakan. Sehingga model AR(1) dan GSTAR $(1,1)$ tidak cocok digunakan pada tiga lokasi, hal ini dikarenakan curah hujan biasanya bersifat musiman.

\section{KESIMPULAN}

Berdasarkan hasil analisis model AR(1) didapatkan hasil estimasi parameter AR(1) hanya Kota Pontianak yang signifikan, sedangkan untuk Kabupaten Mempawah dan Kabupaten Kubu Raya tidak signifikan. Sedangkan standar error masing-masing parameter model GSTAR $(1,1)$ lebih besar sehingga model tidak cocok digunakan pada tiga lokasi. Kemudian, perbandingan MAPE model AR(1) dan model GSTAR(1,1) diketahui nilai MAPE GSTAR(1,1) lebih kecil dari AR(1), namun model GSTAR(1,1) tidak terlalu baik untuk melakukan peramalan. Oleh karena itu, penelitian curah hujan ini perlu dianalisis lebih lanjut dengan metode musiman karena curah hujan biasanya memiliki pola musiman.

\section{DAFTAR PUSTAKA}

[1] Pemerintah Provinsi Kalimantan Barat, Gambaran Umum Aspek Geografis Kalimantan Barat, http://kalbarprov.go.id/page/geografis, diakses tanggal 22 Januari 2020.

[2] Makridakis, S., Wheelwright, S. dan McGee, V. E., Metode dan Aplikasi Peramalan, Edisi kedua, Jilid satu, Jakarta, Binarupa Aksara, 1999.

[3] Pfeifer, P.E. and Deutsch, S.J., A Three-Stage Iterative Procedure for Space Time Modeling, Technometrics, 1980, 22(1): 35-47.

[4] Assauri, S. Teknik dan Metode Peramalan Penerapannya dalam Ekonomi dan Dunia Usaha. Jakarta: Fakultas Ekonomi Universitas Indonesia, 1984.

[5] Suhartono dan Subanar, The Optimal Determination of Space Weight in GSTAR Model by using Cross-correlation Inference, Journal Devoted to the Mathematical and Statistical Aplication in Various Field, 2006, 2(2): 45-53.

[6] Wutsqa, D.U., Suhartono dan Sutijo, B.S.U., Aplikasi Model Generalized Space Time Autoregressive pada Data Pencemaran Udara di Kota Surabaya, phythagoras, 2012, 7(2): 17 30.

[7] Wei, W.W.S, Time Series Analysis: Univariate and Multivariate Methods (2 ${ }^{\text {nd }} e d$ ), Pearson, New York, 2006.

IHZAL MUHAINI

DADAN KUSNANDAR

NURFITRI IMRO’AH
: Jurusan Matematika FMIPA Untan, Pontianak, Ihzalmuhaini26@gmail.com

: Jurusan Matematika FMIPA Untan, Pontianak, dkusnand@untan.ac.id

: Jurusan Matematika FMIPA Untan, Pontianak, nurfitriimroah@math.untan.ac.id 